\title{
Isolation and Characterization of Novel Lytic Phages to Combat Multidrug-Resistant E. coli and Salmonella spp.
}

\author{
Atunga Nyachieo ${ }^{1}$, Stephen Alafi ${ }^{2}$, Ivy Jepkurui Mutai ${ }^{1}$, Benson Ngolobe $^{2}$, Ritah Nabunje ${ }^{2}$, \\ Jesca L. Nakavuma² \\ ${ }^{1}$ Phage Biology Laboratory, Institute of Primate Research, Box 24481-00502, Karen, Nairobi, Kenya \\ ${ }^{2}$ Department of Biomolecular and Biolaboratory Sciences (BBS), College of Veterinary Medicine, Animal Resources \\ and Biosecurity (COVAB), Makerere University, P.O. Box 7062, Kampala, Uganda
}

\begin{abstract}
Objectives: Escherichia coli and some Salmonella enterica serovars are zoonotic pathogens affecting livestock and humans. These pathogens cause significant loss of productivity in livestock, severe morbidity and mortality in humans, and have high antibiotic resistance profiles. Therefore, the exploitation of lytic phages for therapeutic purposes is important for eliminating these resistant bacterial strains.
\end{abstract}

Methods: Thirty-four bacterial stock isolates comprised of 23 E. coli and 11 Salmonella spp. strains were evaluated for antimicrobial susceptibility to seven antibiotics using the Kirby-Bauer disk diffusion test. The antibiotics included Ciprofloxacin, Trimethoprim-Sulphamethoxazole, Gentamycin, Imipenem, Ceftriaxone, Cefotaxime, and Ofloxacin. Twelve (12/23) E. coli and (2/11) Salmonella spp. exhibited antimicrobial resistance. Selected six (6/12) drug-resistant $E$. coli strains were subjected to three different phages (PA5, EHEC005, C11S1A) for efficacy and host range assay. Similarly, two (2/2) resistant Salmonella strains were exposed to one Salmonella phage A23 for efficacy and host range assay. The E. coli (C11S1A) phage, which infected most bacterial hosts, was evaluated for optimal efficiency at various $\mathrm{pH}$ and temperatures.

Results: E. coli isolates had the highest resistance 12/23 (52\%) compared to Salmonella spp. 2/11(18\%) $(p<0.05)$. Most resistance was against Trimethoprim-Sulphamethoxazole (44\%) and (9\%) for E. coli and Salmonella spp., respectively. Furthermore, E. coli (C11S1A) phages killed all the Escherichia coli strains, while Salmonella phage A23 only lysed the host bacteria. The E. coli (C11S1A) phages were highly efficacious at $37{ }^{\circ} \mathrm{C}$ and $\mathrm{pH} 7.4$.

Conclusion: The successful isolation of novel lytic E. coli (C11S1A) phages, which killed all the E. coli strains tested, demonstrates the potential for therapeutic purposes for humans and livestock. $J$ Microbiol Infect Dis 2021; 11(4):183-190.

Keywords: Antimicrobial resistance, zoonosis, novel bacteriophage, East Africa

\section{INTRODUCTION}

Salmonella spp. and Escherichia coli are zoonotic bacteria infecting both humans, livestock, and wildlife [1]. Salmonella serovars belonging to $\mathrm{S}$. enterica subspecies enterica cause $99 \%$ of human and animal infections and can be divided into typhoidal and nontyphoidal Salmonella (NTS) serovars. Non- typhoidal Salmonella (NTS) are among the most common cause of bacterial foodborne zoonoses [2]. Globally, estimates of 17.8 million cases of typhoid and paratyphoid fevers occurred in 2017 [3]. In Sub-Sahara Africa, the prevalence of invasive Salmonella as high as $33 \%$ has been reported [4]. According to previous studies, Salmonella is responsible for 
33,000 incidences of food poisoning annually in Uganda, of which $11.7 \%$ of infections are due to the consumption of contaminated pork [1]. Drugs recommended for the treatment of enteric fever include chloramphenicol, ampicillin and co-trimoxazole, fluoroquinolones, third-generation cephalosporins (ceftriaxone, cefixime), and azithromycin [5]. Management of the Salmonellosis cases by antibiotic administration is hindered by the occurrence of antimicrobial resistance (AMR) even to drugs of greater potency such as ciprofloxacin [3]. The presence of over $50 \%$ multi-drug resistant (MDR) Salmonella typhi in sub-Saharan Africa further compromises this management strategy [4]. In Kenya, multidrug-resistant Salmonella typhi was first reported in the years 1997-1999 at prevalence levels of 50-65\% but has gradually risen to $73 \%$ [6]. In Uganda, reduced susceptibility to ciprofloxacin MDR was detected in TS, and NTS strains from humans, while antimicrobial resistance was reported in $57.7 \%$ NTS, with ciprofloxacin most resisted [7]. Reports of drug resistance in Salmonella isolated from animals and their products exist [8].

Escherichia coli is more frequently isolated compared to Salmonella, and prevalence varies with hosts [9]. In Uganda, drug resistance has been reported in $65.5 \%$, and $10-18 \%$ E. coli isolates from humans and chickens, respectively [10]. A similar scenario exists in Kenya, where a high prevalence of AMR E. coli circulating in humans and livestock was reported [11]. Drug resistance for selected drugs, i.e., tetracycline $(70.7 \%)$, ampicillin $(65.9 \%)$, and sulphamethoxazoletrimethoprim (68.3\%), has been detected in $E$. coli [11]. In Northern Tanzania, over $50 \%$ of the $E$. coli isolates from domestic animals, wildlife, and water sources displayed resistance to at least one antibiotic [12], whereas Salmonella species were resistant to the

third-generation cephalosporin(ceftriaxone), which is the last line antibiotic for Salmonella, in Northwestern Tanzania [13].

Microbial contamination of animal products lowers their quality. The presence of MDR bacteria strains has led to the banning of animal products in certain markets such as the European Union or the USA [14]. Antibiotic use is one of the drivers of drug resistance development, currently a significant threat to global health [15]. Therefore, it is evident that alternatives to antibiotic use are urgently needed to curb antimicrobial resistance, especially the increasing MDR cases. Bacteriophages (phages), the viruses that infect bacteria, have been identified as potential bio-control agents capable of clearing specific strains, including drug-resistant ones. Phages regulate bacterial populations by the induction of lysis and are very abundant in various ecosystems as long as the appropriate hosts are present [16]. The specific lysis is an attribute that has been exploited to develop and produce new therapeutic agents [17]. Currently, bacteriophages are much sought to manage diseases associated with drugresistant bacteria; and can aid in eliminating or preventing the emergence of MDR strains from the farm [18]. In East Africa, there are limited research efforts towards phage therapy, and none has been reported for Salmonella spp. and Escherichia coli, yet these pathogens have been implicated in lowering animal productivity and as well as affecting human health [1]. Therefore, this study sought to determine the in vitro efficacy of selected lytic phages against Salmonella spp. and Escherichia coli which is the basis for the selection of candidates for the development of biocontrol agents.

\section{METHODS}

\section{Study design and source of study bacterial isolates}

An experimental laboratory study was carried out on 34 bacterial isolates (23 E. coli and 11 Salmonella) that were obtained from the stock culture collection from Uganda and Kenya. The test bacteriophages were isolated from sewage, chicken, and gorilla fecal samples. This work was carried out in the Biomolecular Laboratories, Makerere University, Uganda.

\section{Resuscitation of the bacterial isolates and confirmation}

Escherichia coli stock isolates were inoculated in Tryptose Soy broth (Hi-Media, India) and incubated overnight at $37{ }^{\circ} \mathrm{C}$, from which a loopful was sub-cultured on MacConkey Agar (Hi-Media, India). After overnight incubation at $37{ }^{\circ} \mathrm{C}$, suspect colonies were phenotypically characterized by cell morphology, gram staining reaction and confirmed by biochemical tests: Indole, Methyl red, Voges-Proskauer, and Citrate utilization tests as described by 
[19]. The confirmed isolates of $E$. coli were preserved in $30 \%$ glycerol in broth at $-20{ }^{\circ} \mathrm{C}$ until phage analysis. The confirmatory test for Enterohaemorrhagic E. coli (EHEC) and Enterotoxigenic E. coli (ETEC) was done according to the method described by [20), by Polymerase Chain Reaction(PCR) targeting It and sta genes for ETEC, eae gene for atypical and eae and bfp genes for typical EPEC.

Salmonella spp. stock isolates were suspended in Tryptose Soy broth (TSB), and a loopful was transferred from overnight culture to Xylose-Lysine-Dextrose (Hi-Media, India). Following incubation at $37{ }^{\circ} \mathrm{C}$ for about $24 \mathrm{~h}$, Salmonella-suspect colonies, characterized by moist, medium-sized, raised, round margin containing black/dark spot in the center with a translucent edge, were selected. These were further subjected to biochemical tests: citrate utilization, triple sugar iron, and urease test. Finally, those positive for citrate and triple sugar iron but negative for urea utilization were selected and stock culture prepared.

\section{Antimicrobial susceptibility testing}

Antimicrobial susceptibility tests were performed using the disc diffusion method, which was previously described [21]. The susceptibility tests of $E$. coli spp. and Salmonella spp. isolates were done using the commercial antibiotic discs: (Whatman ${ }^{\circledR}$ Antibiotic Assay Discs), Ciprofloxacin (CIP 5 $\mu \mathrm{g}$ ), Trimethoprim-Sulfamethoxazole (SXT 25 $\mu \mathrm{g})$, Gentamycin (GM $10 \mu \mathrm{g}$ ), Imipenem (IPM $10 \mu \mathrm{g}$ ), Ceftriaxone (CRO $30 \mu \mathrm{g}$ ), Cefotaxime (CTX $30 \mu \mathrm{g}$ ), and Ofloxacin (OFX $5 \mu \mathrm{g}$ ). These antibiotics are mostly used in the treatment of E. coli and Salmonella infections in both humans and animals. Therefore, the results were interpreted as percentages.

Phage enrichment, screening, and purification of bacteriophages

Phage enrichment was done using a procedure previously described [22]. Briefly, $20 \mathrm{~g}$ of the sample (wastewater or fecal droppings) was suspended in $80 \mathrm{ml}$ of $\mathrm{SM}$ buffer $(0.05 \mathrm{M}$ Tris, $0.1 \mathrm{M} \mathrm{NaCl}, 0.008 \mathrm{M}$ $\mathrm{MgSO} 4, \quad 0.01 \% \quad \mathrm{w} / \mathrm{v}$ gelatin $\mathrm{pH} \quad 7.5)$, centrifuged at $10000 \times \mathrm{g}$ for $10 \mathrm{~min}$ to remove the large debris and the supernatant filtered into media with host bacteria of interest then incubated overnight at $37{ }^{\circ} \mathrm{C}$. The overnight enriched cultures were then centrifuged at $6000 \times g$ for 10 minutes (Fisher Centrific $®$,
Missouri City, Texas, US), and the supernatant was filtered through a $0.22 \mu \mathrm{m}$ filtration unit. For the phage screening step, $100 \mu \mathrm{l}$ an overnight host bacterium in broth was inoculated in $6 \mathrm{ml}$ molten soft agar $(0.7 \%$ agar with TSB), mixed by inversion, plated in TSA plates, and left to dry with the lid slightly open. The filtrate was serially diluted to tenfold then $5 \mu \mathrm{l}$ of each dilution was spotted in an agar plate with bacteria. The plates were then incubated overnight at $37^{\circ} \mathrm{C}$. The presence of clear zones or plaques was indicated the presence of phages. The plaques were observed after overnight incubation and successive purifications made by suspending the distinct plaque in $200 \mu \mathrm{l}$ in SM buffer. Any filtered phage was preserved in a $30 \%$ glycerol awaiting assay against other isolated bacteria.

\section{Spot assay for in vitro phage host range determination}

The host range was done by spotting phages on different bacterial lawns and then checking for the presence of plaques as described by [22] with slight modifications. Briefly, sterile normal saline of the equivalent volume was dispensed on the lawn at specific sites for the negative control. For positive control, characterized phages of known hosts were used. Briefly, the preserved phages were bulked up using host bacteria. This was done by adding host bacterial in $5 \mathrm{mls}$ of single strength Tryptic Soy Broth (TSB), plus Calcium Chloride followed by overnight incubation at 37 ${ }^{0} \mathrm{C}$. The same was done for other different bacterial cultures for host range analysis. The bulked-up phages were then centrifuged at $6000 \times \mathrm{g}$ for $10 \mathrm{~min}$ and filtered using a $0.45 \mu \mathrm{m}$ filter into a sterile tube. Four $\mathrm{ml}$ single strength TSB with $0.7 \%$ agar was used to make an overlay containing the $100 \mu$ l host bacteria on an already prepared TSA plate (base media) and allowed to solidify. Then $10 \mu \mathrm{l}$ phages were later spotted on the selected bacterial strains for host range assay. The TSA plates were allowed to dry and incubated overnight at $37{ }^{\circ} \mathrm{C}$. The plates were examined for presence or absence of growth-inhibition areas (plaques), and the test bacteria were evaluated as sensitive (+ve) or negative (-ve), respectively. The phage isolate that exhibited Iytic activity against the highest number of bacterial isolates was selected to evaluate each genus's stability at different physicochemical conditions. 


\section{Effect of temperature and $\mathrm{pH}$ on phage stability}

Stability at various $\mathrm{pH}$ levels was tested following the procedure described by [23]. Briefly, the $\mathrm{pH}$ of the SM buffer was adjusted to $4.4,5.4,6.4,7.4,8.4$, and 9.4 using $1 \mathrm{M} \mathrm{HCl}$ and $1 \mathrm{M} \mathrm{NaOH}$. Next, the phage suspensions or lysates were added to the $\mathrm{pH}$-modified SM buffer at a ratio of $1: 9$ and incubated for $60 \mathrm{~min}$ at $37^{\circ} \mathrm{C}$, with gentle shaking at $120 \mathrm{rpm}$. The lysates were then serially diluted to $10-8$ and quantified using the \% reduction or increase in phage titer versus $\mathrm{pH}$ on the spot assayed plates after overnight incubation at $37{ }^{\circ} \mathrm{C}$.

The effect of temperature on phage stability was determined as described by [23]. Briefly, predetermined phage concentration was incubated for 60 mins at various temperatures $\left(4{ }^{\circ} \mathrm{C}, 15{ }^{\circ} \mathrm{C}, 26{ }^{\circ} \mathrm{C}, 37{ }^{\circ} \mathrm{C}, 48{ }^{\circ} \mathrm{C}\right.$, and $\left.59{ }^{\circ} \mathrm{C}\right)$, and the suspension was allowed to get to room temperature $\left(20-27{ }^{\circ} \mathrm{C}\right)$ for 30 minutes before quantification. Then $10 \mu \mathrm{L}$ of each thermally treated phage preparation was added to indicator bacteria and incubated at $37{ }^{0} \mathrm{C}$ overnight. Finally, the effect of temperature was determined by comparing the number of phages in plates of known titer (control) titer with those in study plates done in duplicates.

\section{Data and Statistical analysis}

All tests were carried out using STATVIEW software (version 5.0, SAS Institute Inc., Cary, NC, USA). Using Fischer's exact test, drug resistance profiles (proportion of resistant strains) were compared.

\section{RESULTS}

Overall, E. coli exhibited significantly higher drug resistance $(52 \%, n=23)$ than Salmonella spp. $(18 \%, n=11)$ at $p<0.05$. Most resistance was encountered for Co-trimoxazole at $44 \%$ and $9 \%$ for E. coli and Salmonella spp., respectively. This resistance to TrimethoprimSulfamethoxazole (SXT) was mainly coming from chicken samples $6 / 23(26 \%)$ for $E$. coli and $1 / 11 \quad(9 \%)$ Salmonella spp.. Individual sample on $E$. coli drug resistance was as follows: enterohaemorrhagic $E$. coli (EHEC, cattle $0 / 2(0 \%$, all drugs); enterotoxigenic $E$. coli (ETEC, cattle $1 / 5(20 \%, 1$ SXT), fresh $E$. coli environment $2 / 5(40 \%, 2$ SXT), Chicken $6 / 7(86 \%, 6$ SXT), and stored environmental samples $1 / 4$ (25\%). Only two samples obtained from chicken contained resistant
Salmonella spp. isolate $2 / 11$ (18\%, 1 SXT, 1 IPM), with other samples being sensitive to all the drugs tested. GM resistance was $4.3 \%$ for E. coli and $0 \%$ Salmonella; CTX resistance was $4.3 \%$ E. coli and $0 \%$ Salmonella, and finally, IPM resistance was $0 \% E$. coli and 9.1\% Salmonella spp..

Six selected resistant $E$. coli strains were used for this test concerning phage host range determination. These 6 were: (29522-Uganda (1), ETEC-251(1, cattle), 13F2 (1, cattle), ECO-25922-Kenya (1). E. coli phage PA5 (from sewage) only killed the host (PA5Uganda sample), whereas phage EHEC-015$\mathrm{H} 7005$ (from sewage) killed all the $E$. coli strains except 13F2 (obtained from cattle). In contrast, E. coli phage C11S1A (from chicken) was a novel lytic phage that killed all the $E$. coli strains (Table 1). For Salmonella, Phage A23 (isolated from gorilla fecal matter) only lysed the host salmonella bacteria.

Since novel lytic phage C11S1A (E. coli phage) exhibited a broad host range, it was further tested for $\mathrm{pH}$ and temperature stability. This phage C11S1A exhibited activity at all temperatures, and $\mathrm{pH}$ was evaluated determined through the percentage of plaqueforming units (Figures $1 \& 2$ ). However, it had reduced activity at $\mathrm{pH} 4.4-5.4$, but its efficiency increased at $\mathrm{pH}$ 6.4-9.4 with optimal $\mathrm{pH}$ of 7.4 (Figure 2). Similarly, phage C11S1A had high efficiency at $15{ }^{\circ} \mathrm{C}$ to $48{ }^{\circ} \mathrm{C}$, with an optimal temperature being $37{ }^{\circ} \mathrm{C}$ (Figure 1). However, efficiency was highly reduced at $4{ }^{\circ} \mathrm{C}$ and 59 ${ }^{0} \mathrm{C}$ (Figure 1).

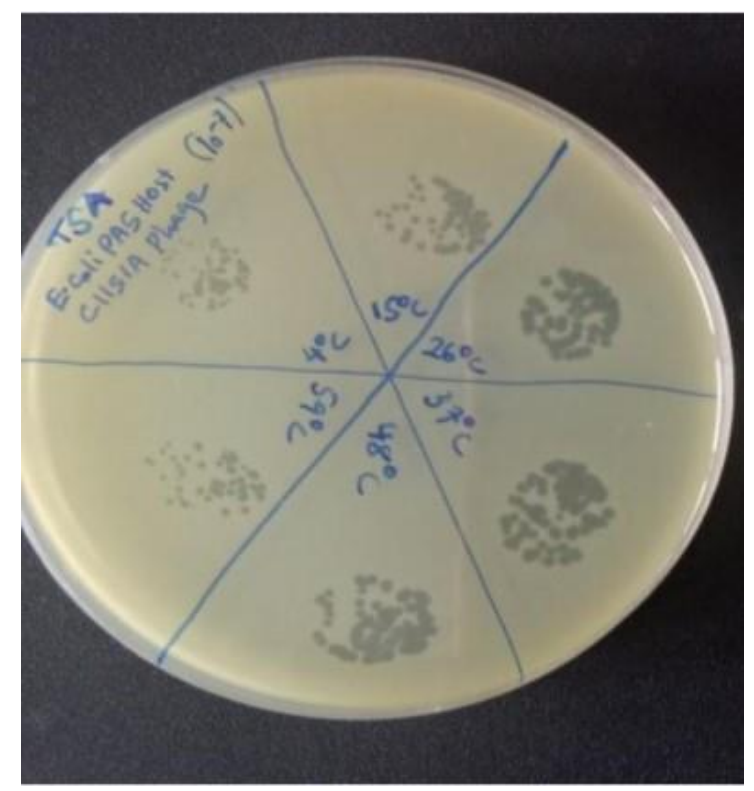


Figure 1. Temperature variation for phage C11SIA phage.

Figure 1 shows that this phage C11S1A exhibited activity at all temperatures evaluated. Our results on temperature indicated that our phage $\mathrm{C} 11 \mathrm{~S} 1 \mathrm{~A}$ has high stability, it had high efficiency at $15{ }^{\circ} \mathrm{C}$ to $48{ }^{\circ} \mathrm{C}$ with an optimal temperature being $37{ }^{\circ} \mathrm{C}$. However, at $4{ }^{\circ} \mathrm{C}$ and $59{ }^{\circ} \mathrm{C}$, efficiency was highly reduced, but with low effectiveness.

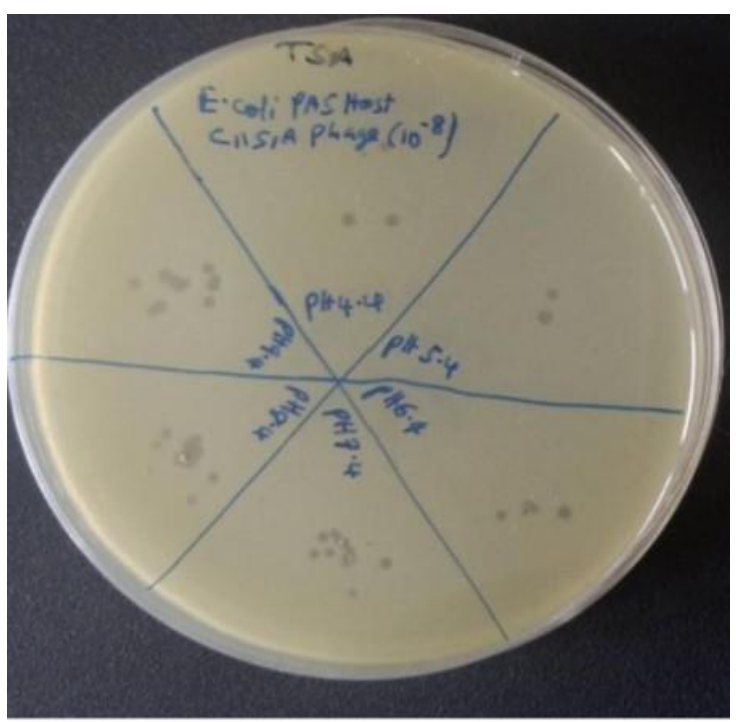

Figure 2. $\mathrm{pH}$ variation for $\mathrm{C} 11 \mathrm{~S} 1 \mathrm{~A}$ phage

Figure 2 shows that this phage C11S1A exhibited activity all $\mathrm{pH}$ evaluated, however, it had reduced activity at $\mathrm{pH}$ 4.4-5.4, but its efficiency increased at $\mathrm{pH}$ 6.4-9.4 with optimal $\mathrm{pH}$ of 7.4 with similar.

\section{DISCUSSION}

Table 1: Host range activity of E.coli phages.
Antimicrobial resistance (AMR) is an emerging global problem that cuts across many diseasecausing pathogens, including $E$. coli and Salmonella spp., which are zoonotic pathogens affecting livestock and humans [1]. Therefore, the exploitation of phages for therapeutic purposes is important for eliminating these resistant bacterial strains [18].

In this study, the highest percentages of drug resistance in isolates of $E$. coli and Salmonella typhi were $52 \%$ and $18 \%$, respectively, with the most resistance was for trimethoprimSulfamethoxazole, SXT (44\%), and (9\%). This resistance to SXT was mainly coming from chicken samples (26\%) for E. coli and (9\%) Salmonella spp.. A similar study about E. coli from chicken and human fecal samples [24] indicated higher resistance from poultry (78.85\% and $23.3 \%$, respectively). This study showed that many drug-resistant human fecal $E$. coli isolates were thought to originate from chicken, and drug-resistant poultry source $E$. coli isolates are likely to have originated from susceptible poultry-source. According to [24], this trimethoprim-Sulfamethoxazole resistance in $E$. coli is correlated with dihydrofolate reductase (DHFR) and dihydropteroate synthase (DHPS) genes in integrons present in E. coli. Transposons, plasmids, and class 1 integrons are responsible for the transmission of multiple antibiotic resistance that may be acquired through mobile genetic elements [25], which also applies to $S$. typhi through horizontal gene transfer [6].

\section{E. coli Phages and Source}

E. coli bacteria

\begin{tabular}{|c|c|c|c|c|c|c|c|c|}
\hline $\begin{array}{l}\text { E. coli } \\
\text { phages }\end{array}$ & $\begin{array}{l}\text { Phage } \\
\text { Source }\end{array}$ & $\begin{array}{c}\text { ATCC } \\
29522 \\
\text { Uganda } \\
\text { (R-CTX) }\end{array}$ & $\begin{array}{c}\text { ETEC } \\
\text { cattle } \\
251(4) \\
\text { (R-SXT) }\end{array}$ & $\begin{array}{c}\text { 13F2(F- } \\
\text { SXT), } \\
\text { cattle } \\
\text { fecal } \\
\text { sample }\end{array}$ & $\begin{array}{l}\text { ECO- } \\
25922- \\
\text { Kenya } \\
\text { (R-GM) }\end{array}$ & $\begin{array}{c}\text { C11S1A(R- } \\
\text { SXT), } \\
\text { chicken }\end{array}$ & $\begin{array}{c}\text { EHEC:0157 } \\
\text { Cattle(S) }\end{array}$ & $\begin{array}{c}\text { PA5 } \\
\text { (Control) }\end{array}$ \\
\hline $\begin{array}{l}\text { EHEC- } \\
015- \\
\text { H7005 }\end{array}$ & Sewage & $+\mathrm{ve}$ & $+\mathrm{ve}$ & -ve & + ve & $+\mathrm{ve}$ & +ve (Host) & $+\mathrm{ve}$ \\
\hline PA5 & Sewage & -ve & $-v e$ & -ve & $-v e$ & $-v e$ & -ve & $\begin{array}{c}+ \text { ve } \\
\text { (Host) }\end{array}$ \\
\hline C11S1A & $\begin{array}{l}\text { Chicken } \\
\text { droppings }\end{array}$ & $+\mathrm{ve}$ & $+\mathrm{ve}$ & $+v e$ & $+v e$ & +ve (Host) & $+\mathrm{ve}$ & $+\mathrm{ve}$ \\
\hline
\end{tabular}


Only one sample obtained from chicken contained resistant Salmonella spp. isolate (50\%, 1 SXT, 1 IPM), with other samples being sensitive to all the drugs tested (Marabou stork, tortoise, snake, and control sample). The sensitivity in these samples indicates that the geographical location and less exposure to humans and livestock results in less spread of antimicrobial resistance than the high resistance in chicken, which has higher proximity to humans and livestock.

In host range determination, phage C11S1A (from chicken droppings) killed all the $E$. coli host strains $(100 \%)$ clearance, making it a super phage and only one phage (A23) sourced from gorilla lysed $S$. typhi. Despite the high resistance of the chicken $E$. coli isolates to the tested antibiotics (26\%), they can also be a good source of phages that are effective in a broader host range and well described in the diverse nature of phages [26].

Host range evaluation is another factor contributing to phage therapy's success, as observed in the E. coli super phage C11S1A (from chicken), which killed all the strains, indicating phages' therapeutic potential on bacterial resistance. The isolation of these phages from various sources and testing them on the resistant strains gives hope to the rising E. coli antimicrobial resistance [6].

This phage C11S1A exhibited activity in all temperatures and $\mathrm{pH}$ evaluated; however, it had reduced activity at $\mathrm{pH} 4.4-5.4$, but its efficiency increased at $\mathrm{pH}$ 6.4-9.4 with optimal $\mathrm{pH}$ of 7.4. Similar observations on varying efficacy due to varying $\mathrm{pH}$ have been described elsewhere [27]. This finding shows that $\mathrm{pH}$ has a significant impact on the adsorption of the phage to the bacteria. The sensitivity of the phage to lower $\mathrm{pH}$ levels might have led to protein denaturation, and hence less the lower plaque counts.

Our results on temperature indicate that our phage C11S1A is high stability; it had high efficiency at $15 \mathrm{OC}$ to $48{ }^{\circ} \mathrm{C}$ with an optimal temperature being $37{ }^{\circ} \mathrm{C}$. Similar observations of varying efficacy on different temperature ranges have been described elsewhere [27]. Temperature is a crucial factor for bacteriophage survivability [28]. However, at 4 oC and 59 oC, efficiency was highly reduced, but with low effectiveness. This shows that at lower than optimal and higher than optimal temperatures, fewer genetic materials penetrate the bacterial cells, and hence fewer of them are involved in the multiplication phase [29].

Although the $E$. coli novel phage C11S1A lysed six different $E$. coli strains indicating its broad host range, we propose that more $E$. coli strains could have been appropriate. For Salmonella, the phage isolated only lysed the host bacteria, and more work is needed to search for new phages with a broad host range.

This study documents the presence of novel lytic phages that are effective on the MDR $E$. coli and Salmonella isolates in East Africa. Furthermore, these phages proved to be more effective than antibiotics, indicating that phages are an excellent source of new antimicrobial agents that contribute to the emerging antimicrobial resistance. Also, isolation of phages from various sources could provide a diverse number of phage strains used in cocktail phage therapy. Lastly, we demonstrated that the physicochemical properties of the phages play a significant role in the efficacy of the phage. Hence, they need to be considered when isolating and storing phages for therapeutic purposes.

\section{ACKNOWLEDGMENTS}

Authors' contribution: All authors provided their input and approval before submission and agreed to the integrity of this study as it has been presented. All the authors conceived of the presented idea. $\mathrm{AN}, \mathrm{JN}, \mathrm{RN}, \mathrm{BN}$, and $\mathrm{SA}$ carried out the experiment. $\mathrm{AN}, \mathrm{JN}$, and IM took the lead in writing the article with input from all authors. JN and AN reviewed the writing process.

Declaration of conflicting interest: The author(s) declare no potential conflicts of interest concerning this article's research, authorship, and/or publication.

Financial disclosure: Funding support was provided by The World Academy of Sciences (TWAS; TYAN Collaborative Grant Award, F.R. 3240301803), awarded to Dr. Atunga Nyachieo. We also appreciate the technical support provided by the Institute of Primate Research (IPR), Nairobi, Kenya, and College of Veterinary Medicine, Animal Resources and 
Biosecurity (COVAB), Makerere University, Kampala, Uganda.

\section{REFERENCES}

1. Kagirita AA, Baguma A, Owalla TJ, Bazira J, Majalija S. Molecular Characterization of Salmonella from Human and Animal Origins in Uganda. Int J Bacteriol. 2017.

2. Andoh LA, Ahmed S, Olsen JE, et al. prevalence and characterization of Salmonella among humans in Ghana. Trop Med Health. 2017; 45(1):3.

3. Antillón M, Warren JL, Crawford FW et al. The burden of typhoid fever in low- and middleincome countries: A meta-regression approach. PLoS Negl Trop Dis. 2017;11(2)

4. Marks $F$, von Kalckreuth $V$, Aaby $P$, et al. Incidence of invasive salmonella disease in subSaharan Africa: a multicentre population-based surveillance study. Lancet Glob Health. 2017 $5(3)$

5. Sirinavin S, Garner P. Antibiotics for treating salmonella gut infections. Cochrane Database Syst Rev. 1999 (1).

6. Kariuki S, Revathi G, Muyodi J, et al. Characterization of Multidrug-Resistant Typhoid Outbreaks in Kenya. J Clin Microbiol. 2004; 42(4):1477-82.

7. Kajumbula $\mathrm{H}$, Fujita AW, Mbabazi $\mathrm{O}$, et al. Antimicrobial Drug Resistance in Blood Culture Isolates at a Tertiary Hospital, Uganda. Emerg Infect Dis. 2018; 24(1):174-5.

8. Nyabundi $\mathrm{D}$, Onkoba $\mathrm{N}$, Kimathi $\mathrm{R}$, et al. Molecular characterization and antibiotic resistance profiles of Salmonella isolated from fecal matter of domestic animals and animal products in Nairobi. Trop Dis Travel Med Vaccines. 2017; 13;3.

9. Langata LM, Maingi JM, Musonye HA, Kiiru J, Nyamache AK. Antimicrobial resistance genes in Salmonella and Escherichia coli isolates from chicken droppings in Nairobi, Kenya. BMC Res Notes. 2019;12(1):22.

10. Kabiswa W, Nanteza A, Tumwine G, Majalija S. Phylogenetic Groups and Antimicrobial Susceptibility Patterns of Escherichia coli from Healthy Chicken in Eastern and Central Uganda. J Vet Med. 2018.

11. Bii CC, Taguchi H, Ouko TT, Muita LW, Wamae N, Kamiya S. Detection of virulencerelated genes by multiplex PCR in multidrugresistant diarrhoeagenic Escherichia coli isolates from Kenya and Japan. Epidemiol Infect. 2005; 133(4):627-33.

12. Subbiah $M$, Caudell MA, Mair $C$, et al. Antimicrobial resistant enteric bacteria are widely distributed amongst people, animals and the environment in Tanzania. Nat Commun. 2020;11(1):228.

13. Moremi N, Claus $\mathrm{H}$, Mshana SE. Antimicrobial resistance pattern: a report of microbiological cultures at a tertiary hospital in Tanzania. BMC Infect Dis. 2016; 16(1):756.

14. Chang $\mathrm{Y}$, Shin $\mathrm{H}$, Lee J-H, Park CJ, Paik S-Y, Ryu S. Isolation and Genome Characterization of the Virulent Staphylococcus aureus Bacteriophage SA97. Viruses. 2015; 7(10):5225-42.

15. Byrne MK, Miellet S, McGlinn A, et al. The drivers of antibiotic use and misuse: the development and investigation of a theory driven community measure. BMC Public Health. 2019;19(1):1425.

16. Wang I-N. Lysis timing and bacteriophage fitness. Genetics. 2006; 172(1):17-26.

17. Oduor JMO, Onkoba N, Maloba F, Nyachieo A. Experimental phage therapy against haematogenous multi-drug resistant Staphylococcus aureus pneumonia in mice. Afr J Lab Med. 2016;5(1):435.

18. Abatángelo $\mathrm{V}$, Bacci NP, Boncompain CA, et al. Broad-range lytic bacteriophages that kill Staphylococcus aureus local field strains. PLOS ONE. 2017;12(7).

19. Lupindu AM. Isolation and characterization of Escherichia coli from animals, humans, and environment. 2017.

20. Seyede TM, Amiri D, Saeid M, Farzaneh K, Saeid B. Identification of different Escherichia coli pathotypes in north and north-west provinces of Iran. Iran J Microbiol. 2017; 9(1).

21. Reller LB, Weinstein $\mathrm{M}$, Jorgensen $\mathrm{JH}$, Ferraro MJ. Antimicrobial Susceptibility Testing: A Review of General Principles and Contemporary Practices. Clin Infect Dis. 2009; 49(11):1749-55.

22. Wommack KE, Williamson KE, Helton RR, Bench SR, Winget DM. Methods for the Isolation of Viruses from Environmental Samples. Totowa, NJ: Humana Press; 2009. p. 3-14.

23. Jończyk E, Kłak M, Międzybrodzki R, Górski A. The influence of external factors on bacteriophages-review. Folia Microbiol (Praha). 2011; 56(3):191-200.

24. Rasheed MU, Thajuddin N, Ahamed P, Teklemariam Z, Jamil K. Antimicrobial drug resistance in strains of Escherichia coli isolated from food sources. Rev Inst Med Trop Sao Paulo. 2014; 56(4):341-6.

25. Colello R, Krüger A, Conza JD, et al. Antimicrobial Resistance in Class 1 Integron- 
Positive Shiga Toxin-Producing Escherichia coli Isolated from Cattle, Pigs, Food and Farm Environment. Microorganisms. 2018;6(4).

26. Keen EC. A century of phage research: Bacteriophages and the shaping of modern biology. BioEssays. 2015;37(1):6-9.

27. Khawaja K, Abbas Z, Rehman S. Isolation and characterization of lytic phagesTSE1-3 against Enterobacter cloacae. Open Life sciences. 2016;11: 287-292.

28. Weinbauer MG. Ecology of prokaryotic viruses. FEMS Microbiol Rev. 2004; 28(2):12781.

29. Cohen ML. Changing patterns of infectious disease. Nature. $2000: 762-767$. 